\title{
THE MEEWASIN VALLEY \\ AUTHORITY'S PROGRAMS FOR 1981-1986
}

LLEN GOULD, Meewasin Valley Authority, 200 - 701 Broadway Avenue, askatoon, Saskatchewan. S7N 1B3

Water has a special significance for eople living in the dry climate of the askatchewan Plains. The Temperance olonists who originally founded askatoon were grateful to reach the helter of the South Saskatchewan River fter their difficult trek across the windwept prairie. The South Saskathewan River valley is no less important or human settlement today. Residents f Saskatoon have the rare privilege of ving in an urban setting where natural egetation extends right into the centre the city. However, the demands on e river and its banks have intensified ith the expansion of Saskatoon. onflicts between uses are becoming hore evident.

The Meewasin Valley Authority 1VA) was established in September, 979 to help its four participating parties the City of Saskatoon, the RM of orman Park, the Provincial Governent, and the University of Saskathewan - protect the river and river illey and resolve river-related land use pnflicts in the municipalities of askatoon and Corman Park. The MVA as also created to initiate projects hich would promote the optimum use the river and its valley as natural sources. In some areas, these procts will make the river valley more cessible to a range of recreational sers; in other areas, where the land is gile or is an important wildlife habitat, e projects will prohibit the kinds of acities which would damage these senive lands.

The MVA's Master Conceptual Plan sets out key principles for the projects the MVA initiates. To quote from the plan:

"The objective is balance. The umbrella idea, the broad concept, is health (defined by the World Health Organisation as a "state of complete physical, mental, and social wellbeing, and not merely the absence of infirmity"). If the continuing physical health of the river and all its connected parts - creek, coulee, ravine, slough, aquifer, land and air, the natural system as a whole - is related, directly and indirectly, to individual health and social health, the supporting concept must be one of fit, the fit of man with this natural system. The theme is linkage: the physical linkage of the city and rural areas to each other and to the river and the natural system, the social linkage of people to people; the linkage of time - past, present and future."

Balance, health, fit, linkage - four principles which together suggest a vision of how the river valley should evolve. They hold out the promise that the process of urbanisation need not represent the threat to the environment usually associated with the growth of cities.

The principles of the Master Conceptual Plan are made concrete in the MVA's development plans. In drawing up its first development plan, the MVA has concentrated on establishing policies and planning projects for four programs. These are: the Waterfront Program, the Heritage Resources Program, the Land Resources Program, 


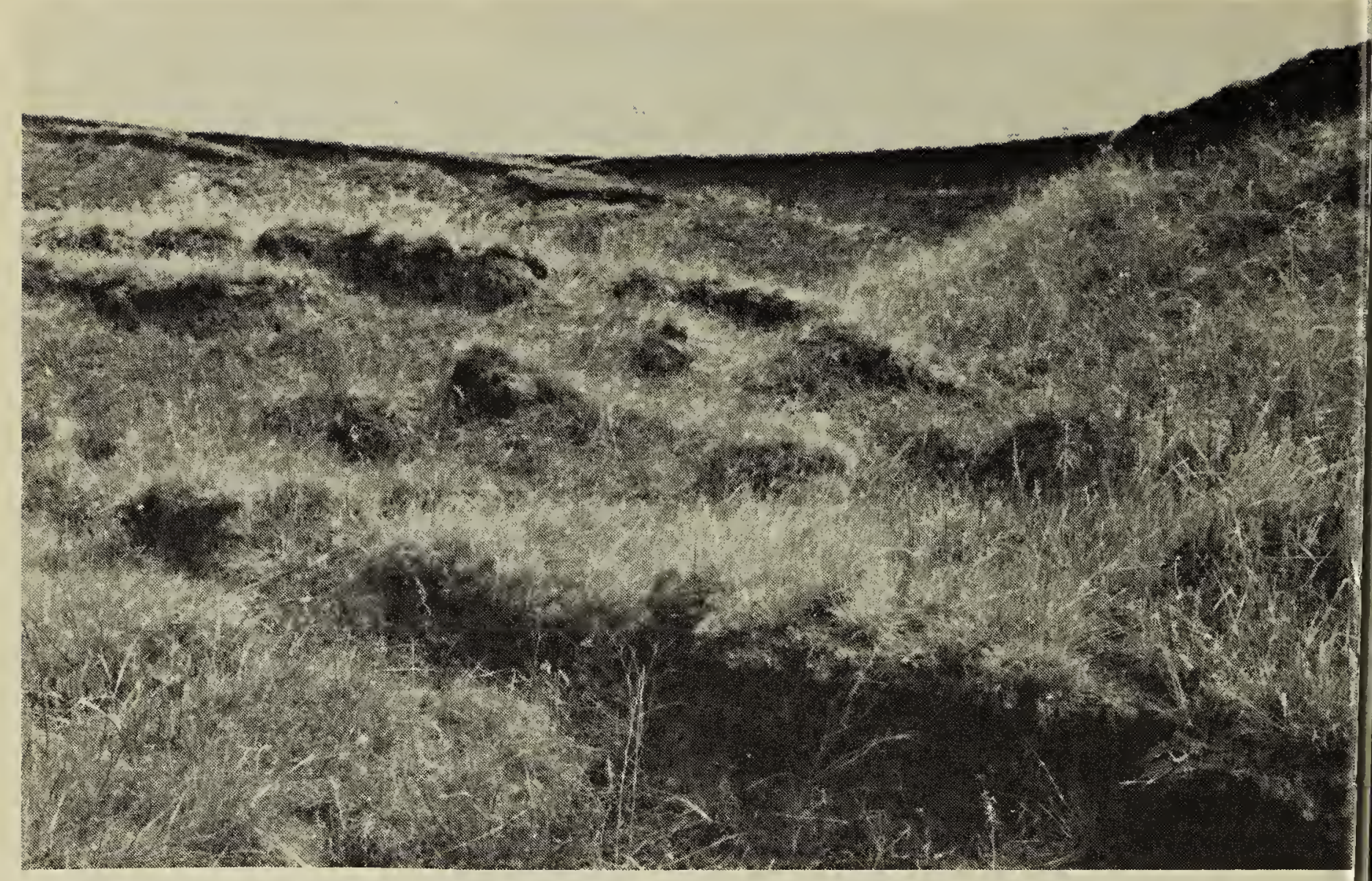

The MVA will identify hazard lands in the valley such as this slumping bank.

and the River Resources Program. All of the MVA's projects over the next five years will contribute to the goals of these four programs.

Under its Waterfront Program, the MVA will concentrate on the development of parks for recreational purposes and on enhancing the scenic features of parts of the river bank. The project which will probably have the highest visibility will be the MVA's involvement in the development of the South Downtown Concept. The South Downtown Concept provides for the urban development of the southern end of Saskatoon's downtown in a way that will draw the full benefit from the scenic and recreational potential of the waterfront.

At the same time, the MVA will be participating with other agencies in the assembly of land for, and the development of, waterfront parks. An illustration on how the MVA will go about park development in conformity with the principles of health, fit, balance, and linkage is represented in the $w_{i}$ Meewasin Park will be develope Meewasin Park is a 250-acre park e tending from the site of the proposi 42nd Street Bridge north to the city lim along the west bank of the river. $T$ plans for the Park are designed promote the health of the natural are along the river bank and provide for $t$ kinds of human activities which will conflict with the preservation of the isting natural areas within the $\mathrm{Pa}$ where in addition to the native flor considerable wildlife populati flourishes.

One aspect of Meewasin Park contribute to another of the MVA's gc - that of developing a link with past. Under the MVA's Herite Resources Program, archaeologi and historic sites in the Park will developed along with interpret programs for these sites.

The Heritage Resources Program also involve the MVA in the restora of Riel House, the oldest structure 


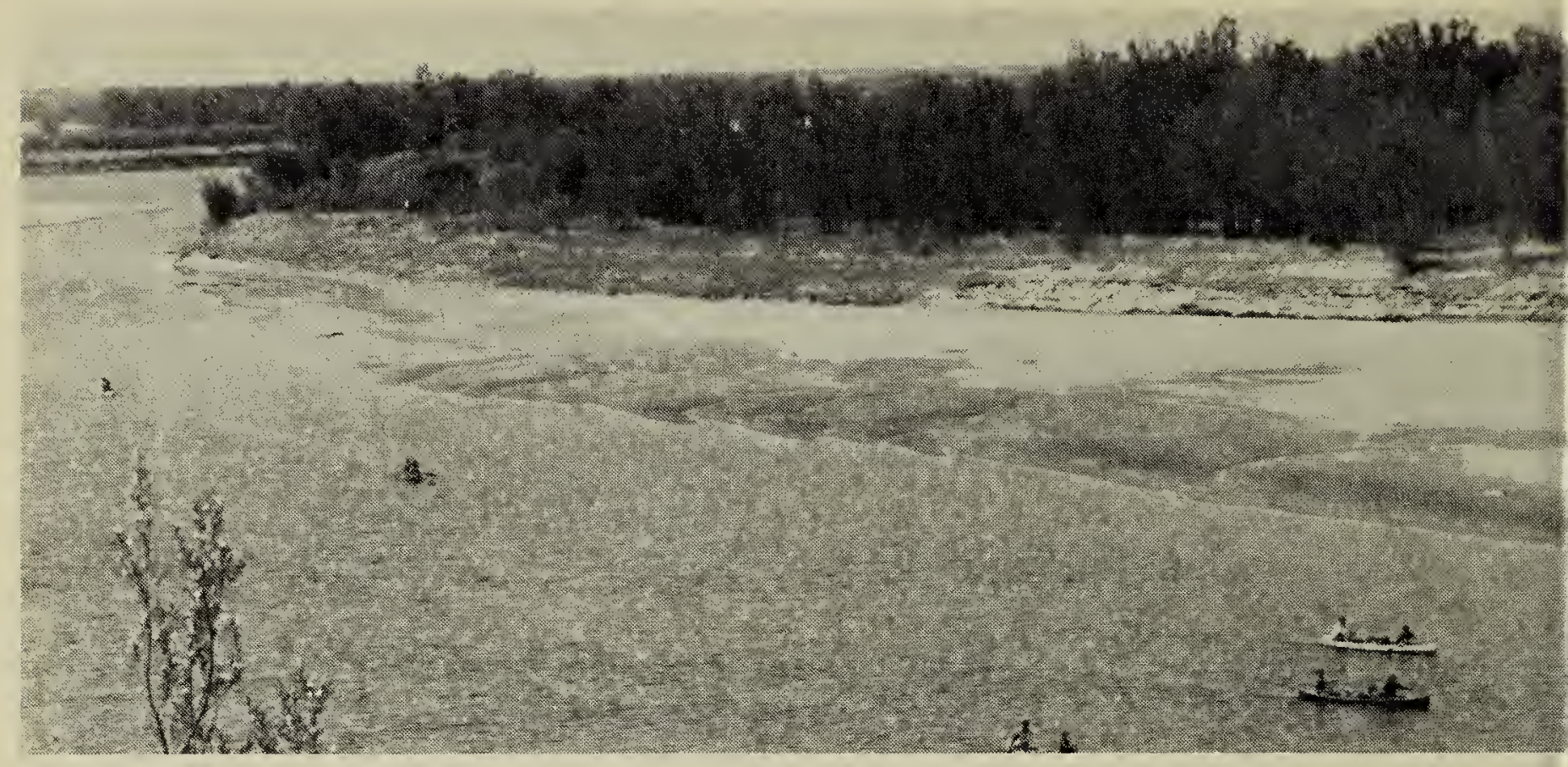

The River Task Force is helping the MVA explore the recreational potential of the South Sask atchewan River.

water pollution, land filling and erosion, and the quantity of water needed for the many uses to which the river is put. In order to draw on the expertise of those already working on these issues, the MVA has established a River Task Force which will help to establish policies and guidelines related to river use.

All four of the MVA's programs will have both an educational component and ways for people to become involved. This two-way flow of information will be accomplished in a variety of ways.

The education component will take the form of environmental awareness projects carried out in cooperation with the schools, the gathering and distribution of information materials on the river and its valley, and the opening of an interpretation centre. The MVA's interpretation centre will include displays on both the natural and cultural history of the Meewasin Valley. There will also be specific projects designed to promote an awareness of environmental concerns, such as the yearly MVA Clean-Up Campaign.

The public's involvement in the MVA's programs is a necessary part of their implementation. The very existence of the MVA reflects a strong interest or the part of the local community in the health of the river valley and the MVA has instituted ways for people to offe their advice and suggestions. The creation of opportunities for people to get involved is a constant of every MVA project. These opportunities take th form of open houses, public meeting and informal meetings which can $b$ held at the request of interested in dividuals. In addition, four communit advisory committees have been es tablished to advise the MVA on its fou programs. The committees are made $u$ of individuals from the community an of representatives of a number organisations; e.g. the Natural Histor Society will name a representative to th Land Resources Advisory Committer The Authority considers these com mittees to be essential to the success the MVA's programs.

It is no accident that so much of th natural vegetation along the river bar has been preserved. It took foresig and planning to preserve these areas the face of urbanisation. With the inter sifying pressures resulting from rap urban growth, even more foresight ar planning will be required in the futur 